\title{
Effects of Team Identification on Social and Emotional Adjustment in Higher Education
}

\author{
Gi-Yong Koo \\ Troy University \\ Junmo Sung \\ University of Arkansas \\ J. Michael Martinez \\ Louisiana State University
}

\begin{abstract}
Students who highly identify with a team are likely to share a personal selfconcept with larger groups in higher education. The improved self-worth is positively associated with the adjustment to college life, and is considered one of the significant predictors to achieve students' educational goals. However, little research has been conducted to scrutinize the effects of team identification on school adjustment. The purpose of this study, therefore, was to examine direct and indirect relationships among team identification, personal self-esteem, and school adjustment. A total of 254 undergraduate students at a FBS institution in the southeastern region of the United States participated in the study. The results revealed that the higher team identification students possess, the higher personal worth they feel. In addition, team identification and personal self-esteem led to social adjustment while personal self-esteem and social adjustment had a positive impact on emotional adjustment. By understanding team identification as an important academic facilitator, administrators in both the academic and athletic fields can develop the most appropriate environment for students to enhance their adjustment to college life.
\end{abstract}

Keywords: intercollegiate athletics, team identification, social adjustment, emotional adjustment

\footnotetext{
Koo is with the School of Hospitality, Sport, \& Tourism Management, Troy University, Troy, AL. Sung is with Health, Human Performance and Recreation, University of Arkansas, Fayetteville, AR. Martinez is with the School of Kinesiology, Louisiana State University, Baton Rouge, LA. Address author correspondence to Gi-Yong Koo at wkoo@ troy.edu.
} 
A social group includes two or more individuals who pursue a reciprocal relationship, share similar characteristics, and collectively practice affiliation (Correll \& Park, 2005). A number of social scientists have been interested in the benefits derived from social group membership. The valued social group can deliver intangible benefits to the individuals via improving social and emotional relationships with the in-group members (Tajfel, 1981; Turner, 1975). In higher education, the individual commitment and psychological connection students have with their sport entities play a significant role in building a social group because the highly identified individuals easily associate with others in the circumstances where team, coach, or athletics is similarly supported (Koo \& Hardin, 2008; Sutton, McDonald, Milne, \& Cimperman, 1997; Wann \& Pierce, 2005). This theoretical concept has been well developed as team identification reflecting "a central component of one's overall social identity” (Theodorakis, Wann, \& Weaver, 2012, p. 80).

Numerous studies extensively employed team identification to predict consumer behaviors including merchandise purchases (Lee, Shin, Park, \& Kwon, 2010; Trail, Anderson, \& Fink, 2000), game attendance (Madrigal, 1995), and fan motivations (Fisher \& Wakefield, 1998; Koo \& Hardin, 2008; Kwon \& Armstrong, 2004). In particular, Wann and colleagues have given great attention to the relationship between team identification and psychological well-being (e.g., Wann, 2000, 2006; Wann, Dunham, Byrd, \& Keenan, 2004; Wann \& Pierce, 2005; Wann \& Weaver, 2009). However, little research has been conducted to comprehensively learn whether team identification either directly or indirectly triggers college adjustments. The purpose of this study, therefore, is to examine the direct and indirect effects of team identification on personal self-esteem, social adjustment, and emotional adjustment.

This study has both theoretical and practical implications. First, findings of this study could extend, theoretically, the existing research on the effects of intercollegiate athletics via scrutinizing whether team identification is associated with social and emotional adaption to college life beyond variance explained by personal self-esteem. Second, findings provide a practical aspect of why the development of an ideal student environment through intercollegiate athletics is beneficial in higher education.

\section{Theoretical Framework}

Over the last several decades, social identity theory has been best recognized as a theory that properly explains the intangible benefits of social group membership. This theory suggests that an individual could improve personal self-esteem through an association with a social group (Tajfel, 1981; Tajfel \& Turner, 1979). In view of that, emotional attachment to the preferred group plays a major role in increasing personal-self-esteem and assisting psychological well-being. For instance, an individual who is highly affiliated with the group is more likely to share a personal self-concept (i.e., personal sense of who I am) with the in-group members (Branscombe \& Wann, 1991; Brewer, 1979; Wann, 2000). Active interaction with the in-group members lets individuals compare themselves with rival groups resulting in significant emotions and values toward the associated group (Tajfel, 1981). This circumstance might produce derogatory feelings about the out-group as well as 
boost an individual's personal self-esteem as a result of the level of affiliation with the in-group (Branscombe \& Wann, 1994; Tajfel, 1981).

In a more specific sports context, social identity theory has primarily been applied in the examination of team identification of sports fans on a variety of levels (Branscombe \& Wann, 1991; Heere \& James, 2007b). Heere and James (2007b) suggest that using the team as one of the in-groups through which membership provides "value and emotional significance" (p. 66). Essentially, this viewpoint allows for fans to be more than simply consumers of the sport experience (Heere \& James, 2007a). Previous research indicates that there are several fan segments for sports teams, with segments for college sports teams being rather unique because of the added segments of students and alumni (Boyle \& Magnusson, 2007). For this reason, scholars have explored team identification using college students as a sample (e.g., Swanson, Gwinner, Larson \& Janda, 2003). In the context of higher education, students are one such fan segment that is motivated to identify with a certain college sport team, and in turn positively interact with the affiliated group members following the team (Wann, 2000). Therefore, the current study employs social identity theory as a theoretical base to explain the linkage of team identification with personal self-esteem and school adjustment.

\section{Effects of Team Identification on Personal Self-Esteem}

Wann (2000) purported that individuals highly identified with a team were more likely to reflect personal self-concept through maintaining social connections with associated group members. Team identification has a significant impact on psychological well-being including high personal self-esteem, low alienation, low depression, and low loneliness (Branscombe \& Wann, 1991; Wann, 2006). The Psychological Health Model proposed by Wann (2006) specified that higher levels of team identification led to greater psychological well-being (e.g., personal self-esteem) caused by the cultivation of social and emotional connections with in-group members. Researchers have indicated an important role of basking-inreflected-glory (BIRGing), and cutting-off-reflected failure (CORFing) phenomenon to reveal fan group connection and psychological attachment, while also suggesting that team success can enhance self-esteem (Branscombe \& Wann, 1991; Brewer, 1979; Murrell \& Dietz, 1992; Oakes \& Turner, 1980; Turner, 1975; Wann, 1996; Wann \& Branscombe, 1990). The studies indicated that individuals who have strong identification desire to maintain BIRGing and reduce a distance with a certain team even though the team has not had much success in the past years. In addition, they evaluate the team as a portion of their life, improving self-esteem. In contrast, individuals with low identification employ CORFing tactics and when the team is failing, distance themselves from the team and membership in that social group (Branscombe \& Wann, 1990; Brewer, 1979; Murrell \& Dietz, 1992; Oakes \& Turner, 1980; Turner, 1975; Wann, 1996; Wann \& Branscombe, 1990).

This relationship is consistent with numerous studies demonstrating that an individual's high association with a favorite team has more powerful emotions of self-worth and positive effects on personal sense of who they are (Branscombe \& Wann, 1991; Brewer, 1979; Oakes \& Turner, 1980; Turner, 1975; Wann, 2000). 
Highly identified fans not only associate with each team, but they often associate with the brand on a deeper level. This is evident in higher education whereby students often present themselves as a part of their athletic teams. For example, students who attend Florida State or Louisiana State may consider themselves as Seminoles or Tigers, respectively. The more students identify with the team, the stronger social group memberships they experience, which in turn, foster personal self-esteem of the students. Intercollegiate athletics, therefore, enable students to interact with other students and to strengthen their personal self-concept through the affiliation with the team (e.g., team identification).

\section{Effects of Personal Self-Esteem on School Adjustment}

Along with the benefits of social connections, which, in turn, result in positive personal self-esteem, a student's psychological well-being has been considered as one of the significant facilitators to achieve his/her educational goals (c.f., Pedrotti, Edwards, \& Lopez, 2008; Pittman \& Richmond, 2007, 2008; Shankland, Genolini, Franca, Guelfi, \& Ionescu, 2010). Pittman and Richmond (2008) examined the impact of a sense of school belonging on psychological and academic adjustment. They revealed that students who had a higher sense of university belonging were shown to possess higher levels of positive self-worth and perceived scholastic competence. Simek (2013) also purported that positive evaluation of self was positively interrelated with happiness and satisfaction with life, as well as negatively associated with fears and anxiety. These findings were consistent with Wann, Brewer, and Royalty (1999) supporting that personal self-esteem was correlated with various psychological conditions of an individual such as decreased anxiety and increased life satisfaction.

Intercollegiate athletics is often considered as one of the potential outlets that facilitate the student's adaption to the complex nature of college life and has been regarded as an influential component to enhance university communality in higher education. A student's social and emotional adjustment could be determined by "becoming integrated into the social life of college, forming a support network, and managing new social freedoms" (Gerdes \& Mallinckrodt, 1994, p. 281). For instance, students highly associated with the team have more opportunities to socially and emotionally interact with the in-group members, which, in turn, magnify their personal self-esteem (Branscombe \& Wann, 1994; Correll \& Park, 2005; Tajfel, 1981; Turner, 1975; Wann, 2000; Wann \& Pierce, 2005). Conversely, students who have difficulty making social and emotional adjustment to college life feel more homesickness and loneliness (e.g., Gerdes \& Mallinckrodt, 1994; Houston, 1971; Lokitz \& Sprandel, 1976; Rich \& Scovel, 1987).

A strong sense of attachment to the sports team is one of factors influencing the extent to which students interact with one another while activities surrounding attendance at collegiate athletic events serve as a surrogate for the more intimate community-building activities (Toma, 1998). Students with a high level of personal self-esteem derived from identification with intercollegiate athletics would experience a high level of social or emotional adjustment as compared with those individuals having a low level of personal self-esteem (Arndt, Greenberg, Schimel, 
Pyszczynski, \& Solomon, 2002; Tajfel, 1981). As a result, it is conceptually evident that personal self-esteem derived from team identification is positively related with social and emotional adjustments to college life (Bettencourt \& Dorr, 1997; Simek, 2013). The forgoing discussion leads to the following research hypotheses (RH):

- $\mathrm{RH}_{1}$ : Team identification with a college athletics program has a positive impact on personal self-esteem.

- $\mathrm{RH}_{2}$ : Personal self-esteem has a positive impact on social and emotional adjustment.

- $\mathrm{RH}_{3}$ : Team identification with a college athletics program has a positive impact on social and emotional adjustment.

Finally, a conceptual model reflecting the research hypotheses is shown in Figure 1.

\section{Method}

\section{Participants}

A convenient sample of 254 undergraduate students enrolled in a major public university in the southeastern region of the United States was recruited for this study. In addition, the university sampled was traditionally successful, ranked in top 30 in all-time win-loss records reported by NCAA in 2013. Despite the lack of external validity, the university sampled was considered a good example to support an important role of intercollegiate athletics (i.e., team identification) in terms of attendance and winning (Wann, Tucker, \& Schrader, 1996).

Of the total 254 students, $131(51.6 \%)$ were male and $123(48.4 \%)$ were female including 50 freshmen $(19.7 \%), 88$ sophomores $(34.6 \%), 64$ juniors $(25.2 \%)$, and 52 seniors $(20.5 \%)$. The majority of students $(96.1 \%)$ were between the ages of 18 and 25 while the mean age of participants was 20.64 years $(S D=2.38)$.

\section{Data Collection Procedure}

This study employed a cross-sectional quantitative survey design. A sample of undergraduate students was chosen from the 12 general elective courses offered

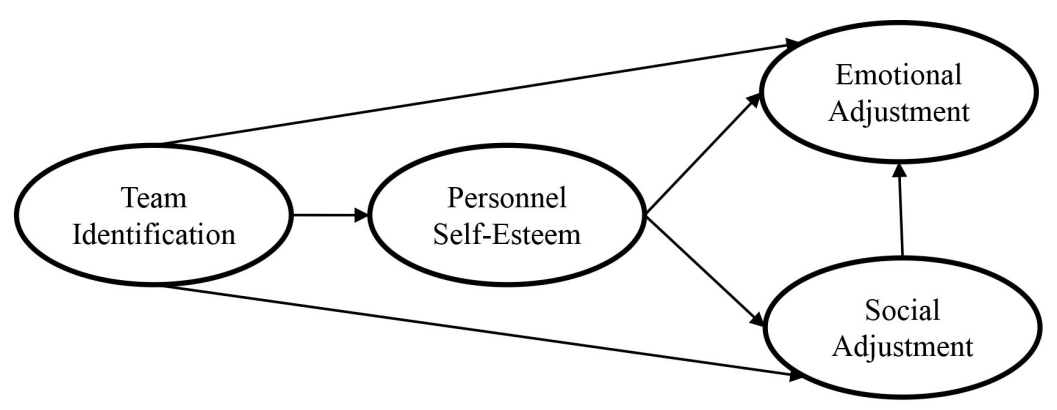

Figure 1 - The Conceptual Model of the Study 
by the Department of Health, Human Performance and Recreation throughout the university. Students were contacted via e-mail and were asked to complete a self-administered on-line survey. McDonald and Adam (2003) suggested that an on-line survey has some advantages such as lower costs, higher response rate, and lower rate of missing data as compared with traditional ones (e.g., pen-paper and telephone methods). In this study, completion of the survey was voluntary and therefore students could choose not to complete the questionnaire anytime during their participation. To increase the response rate, students who did not respond to the initial request also received a follow-up e-mail requesting their participation within the first week of the initial request. As a result, of the 386 students who were contacted by e-mail, 254 students voluntarily completed the on-line questionnaire which resulted in a $65.8 \%$ response rate.

\section{Measures}

All latent constructs employed multi-item scales and were measured by a 5-point Likert type scale anchored by strongly disagree (1) and strongly agree (5). Researchers considered the use of parsimonious measures by reducing the number of items in each inventory, without altering the latent construct. This approach might avoid "a response tendency resulting from the length of a group administered questionnaire instrument" (Herzog \& Bachman, 1981, p. 549). Details of the four major psychological properties (e.g., team identification, personal self-esteem, emotional adjustment, and social adjustment) in the conceptual model were as follows.

First, team identification was measured by a five-item scale adopted from Wann and Branscombe's (1993) Spectator Sport Identification Scale (SSIS). While the original SSIS contained seven items, the current study employed five items, slightly modified to serve the operational definition of team identification, reflecting the degree to which students experience a sense of belonging to a certain team. A reduced subscale for team identification has been widely used in the field of sport management (c.f., Lee, Shin, Park, \& Kwon, 2010; Madrigal \& Chen, 2008) while the omitted two items were considered not to fit the current study. Researchers focused on an individual's personal self-esteem as a result of in-group interaction rather than out-group derogation (e.g., rivalries) as well as viewed team winning as a preliminary condition that would have an impact on other items in the SSIS. Thus, the five items chosen from the SSIS to examine a sense of belonging to the team were: (a) My friends strongly see me as a fan of (the team); (b) I strongly see myself as a fan of (the team); (c) I display (the team)'s name or insignia at my place of work, where I live, or on my clothing; (d) It is important to be a fan of (the team); (e) I regularly follow (the team). Although Wann and Branscombe (1993) reported an internal consistency of 0.91 for the SSIS, the reliability of the current scale was .93. Therefore, the scale of team identification was considered to have an acceptable level of reliability exceeding the .70 threshold (Nunnally \& Bernstein, 1994).

Second, personal self-esteem, reflecting the degree to which students perceive their own overall self-worth or value, was measured by a five positive-wording item scale adopted from Rosenberg (1979). Although the Rosenberg Self-Esteem Scale (RSES) contained a total of 10 questions, consisting of five positive-wording and five negative-wording items (Rosenberg, 1979), researchers intended to employ 
positive wording items to minimize the possibility of accidentally agreeing with negative questions as well as errors in coding caused by the reverse scales (Sauro \& Lewis, 2011). However, of the chosen five items, two items (e.g., I take a positive attitude toward myself; On the whole, I am satisfied with myself) had low-squared multiple correlations decreasing the reliability of the measure. As a result, the current study eventually employed a three-item scale to measure personal self-esteem which included: (a) I feel that I have a number of good qualities; (b) I feel that I am a person of worth, at least on equal basis with others; (c) I am able to do things as well as most other people. Although the original RSES reported an internal consistency of .86 , the reliability of the three-item sale was .75 demonstrating an acceptable level of reliability (Nunnally \& Bernstein, 1994).

Third, a five-item scale, adopted from the Perceived Stress Scale 10 (PSS-10) introduced by Cohen, Kamarck and Mermelstein (1983), was slightly modified and applied to measure emotional adjustment reflecting the degree to which students are satisfied and confident with their school life. For example, one from the PSS-10 read, "In the last month, how often have you felt that things were going your way?". Researchers adapted this item to read, "I feel that things are going my way at school". Thus, the five items to measure emotional adjustment were: (a) I am happy with my school life; (b) I feel confident about handling my school life; (c) I deal successfully with irritating life hassles at school; (d) I am able to control irritations in my school life; (e) I feel that things are going my way at school. Using a reduced subscale to examine perceived stress has been acceptable as the reduced versions did not significantly change the results and alter the structural integrity of the latent construct (c.f., Cohen, Kamarck, \& Mermelstein, 1983; Cole, 1999). In addition, Cohen, Kamarck, \& Mermelstein (1983) demonstrated strong evidence for unidimensionality among items in the PSS-10. While the original PSS-10 reported an internal consistency of .73, Cronbach's reliability alpha of .85 for the current study revealed an acceptable level of internal consistency (Nunnally \& Bernstein, 1994).

Finally, social adjustment was measured by a six-item scale adopted from the UCLA (University of California, Los Angeles) Loneliness Scale developed by Russell, Peplau, and Ferguson (1978). Researchers intended to choose positive wording items to minimize errors in coding and survey responses caused by the reverse scales (Sauro \& Lewis, 2011). While the original scale contained nine positive wording items, the current study initially selected six items that we were considered properly serving our operational definition of social adjustment: the degree to which students are able to integrate themselves into the social groups. However, of the chosen six items, two items (e.g., There are people who really understand me; I feel in tune with the people around me) were considered to have low-squared multiple correlations resulting in a decrease in the reliability of the measure. The current study, therefore, employed a four-item scale to measure social adjustment which included: (a) I feel part of a group of friends; (b) I have a lot in common with the people around me; (c) There are people I can turn to; (d) I am able to do things socially with my friends (e.g., visiting, entertaining, and going out together). Since an internal consistency for social adjustment was .85 exceeding the .70 threshold, the current scale was considered to be just as acceptable (Nunnally \& Bernstein, 1994) as the original UCLA Loneliness Scale reporting an internal consistency of .73 (Russell, 1996). 


\section{Data Analysis}

Data were analyzed using the IBM SPSS 20.0 and EQS 6.1 programs. All measurement and structural equation models were examined using the covariance matrix and maximum likelihood estimation (Bentler \& Hu, 2005). Before evaluating the decomposition of structure effects, a confirmatory factor analysis (CFA) was employed to examine psychometric evaluation of the measures including convergent validity and discriminant validity. Decomposition of the significant direct and indirect relationships among the latent constructs (e.g., team identification, personal self-esteem, social adjustment, and emotional adjustment) was scrutinized by assessing the structural equation model (SEM). The estimates of various fit indices also determined whether the proposed SEM had a favorable model fit to the observed data.

\section{Results}

\section{Means, standard deviations, and correlations}

The means and standard deviations of latent constructs were demonstrated in Table 1. Personal self-esteem $(M=4.21)$ had the highest mean followed by social adjustment $(M=4.10)$, emotional adjustment $(M=3.86)$, and team identification $(M=$ 3.80). The standard deviations ranged from .54 for personal self-esteem to 1.04 for team identification. In addition, an examination of correlation matrix indicated moderate discriminant validity among the latent constructs although all correlation coefficients were statistically significant at .05 level. Of the six correlation coefficients, four correlations did not meet the recommended cut-off point of the $r<$ .50 , probably violating linear independency (George \& Mallery, 2000). However, the decision was made to use all four latent constructs in the further analysis as the previous literature suggested that they were theoretically different psychological properties. In addition, Mertler and Vannatta (2001) recommended merging highly correlated variables as a solution when the correlation coefficient is greater than .80. But, none of the correlations in this study was of that magnitude.

\section{Table 1 Correlation Matrix, Means, and Standard Deviations}

\begin{tabular}{lcccccc}
\hline Factors & $\mathbf{1}$ & $\mathbf{2}$ & $\mathbf{3}$ & $\mathbf{4}$ & Mean & Std. Dev. \\
\hline Team Identification & 1 & & & & 3.80 & 1.04 \\
$\begin{array}{l}\text { Personal Self- } \\
\text { esteem }\end{array}$ & $.298^{* * *}$ & 1 & & & 4.21 & .54 \\
$\begin{array}{l}\text { Emotional Adjust- } \\
\text { ment }\end{array}$ & $.355^{* *}$ & $.532^{* *}$ & 1 & & 3.86 & .67 \\
Social Adjustment & $.533^{* *}$ & $.539^{* *}$ & $.546^{* *}$ & 1 & 4.10 & .71 \\
\hline
\end{tabular}

Notes. $* p<.05, * * p<.01, * * * p<.001$ 


\section{Psychometric Evaluation of the Measures}

A confirmatory factor analysis (CFA) was employed to examine whether the items actually measure each related latent construct as well as whether a latent construct is distinct to the other constructs (Hair, Black, Babin, Anderson, \& Tatham, 2006).

As shown in Table 2, evidence of convergent validity was found by calculating average variance extracted (AVE) of each latent construct. As the estimated AVE were greater than a 0.50 cutoff threshold ranging from .736 to .818 for all latent constructs, the measures were considered to possess acceptable levels of convergent validity. In addition, evidence of discriminant validity was determined by comparing the AVE with the square of the correlation between the latent construct and the other latent constructs, respectively (Hair, et al., 2006). As the calculated AVE for each latent construct was greater than the squared phi correlations $\left(\phi^{2}\right)$ in the measurement model, the measures were found to have satisfactory levels of discriminant validity.

The estimates of exact, absolute, parsimonious, and incremental fit indices demonstrated a favorable model fit for the initial measurement model: $\chi^{2}(129)=$ 232.893, $p$ <.001; Standardized Root Mean Squared Residual $($ SRMR $)=.052$; Root Mean Square Error of Approximation (RMSEA) = .065; Comparative Fit Index $(\mathrm{CFI})=.952$. The Lagrange Multiplier $(\mathrm{LM})$ tests suggested that the model would fit slightly better if the covariance of one pair of error terms were allowed to be freely estimated. Therefore, the final measurement model allowed the covariance of error terms because the modification was supported by the theoretical rationale. For instance, the pair of error terms that were allowed to freely estimate was, I deal successfully with irritating life hassles at school and I am able to control irritations in my school life. While two items assessed the same construct, the error terms could be allowed to covary each other. All fit indices for the modified measurement model met the recommended values specifying a good model fit to the data $(\mathrm{Hu}$ \& Bentler, 1999; Kelloway, 1998): $\chi^{2}(333)=208.378, p<.001, \mathrm{SRMR}=.05$, $\mathrm{RMSEA}=.058, \mathrm{CFI}=.962$. The selected model indices recommended the use of the modified measurement model as part of a structural model examining causal relationships among the latent constructs.

\section{Decomposition of the SEM}

As shown in Table 3, the model indices derived from the $S E M$ revealed a good fit to the data; $\chi^{2}(113)=208.747, p<.001, \mathrm{SRMR}=050, \mathrm{RMSEA}=.058, \mathrm{CFI}=.962$, and all estimated parameters were significant. Although the results of the LM test suggested model modifications which would provide a slightly better fit to the data, the recommended modifications were not theoretically justifiable. Therefore, no additional path was included in the $S E M$ for the further consideration.

First, decomposition of significant relationships derived from the SEM revealed that students' higher levels of team identification predicted were associated higher levels of self-esteem $(t=4.838, p<.05)$. Approximately $13 \%$ of the variance in personal self-esteem was explained by team identification.

Second, students' team identification was positively related to higher levels of social adjustment in higher education $(t=6.450, p<.05)$ while personal self-esteem 


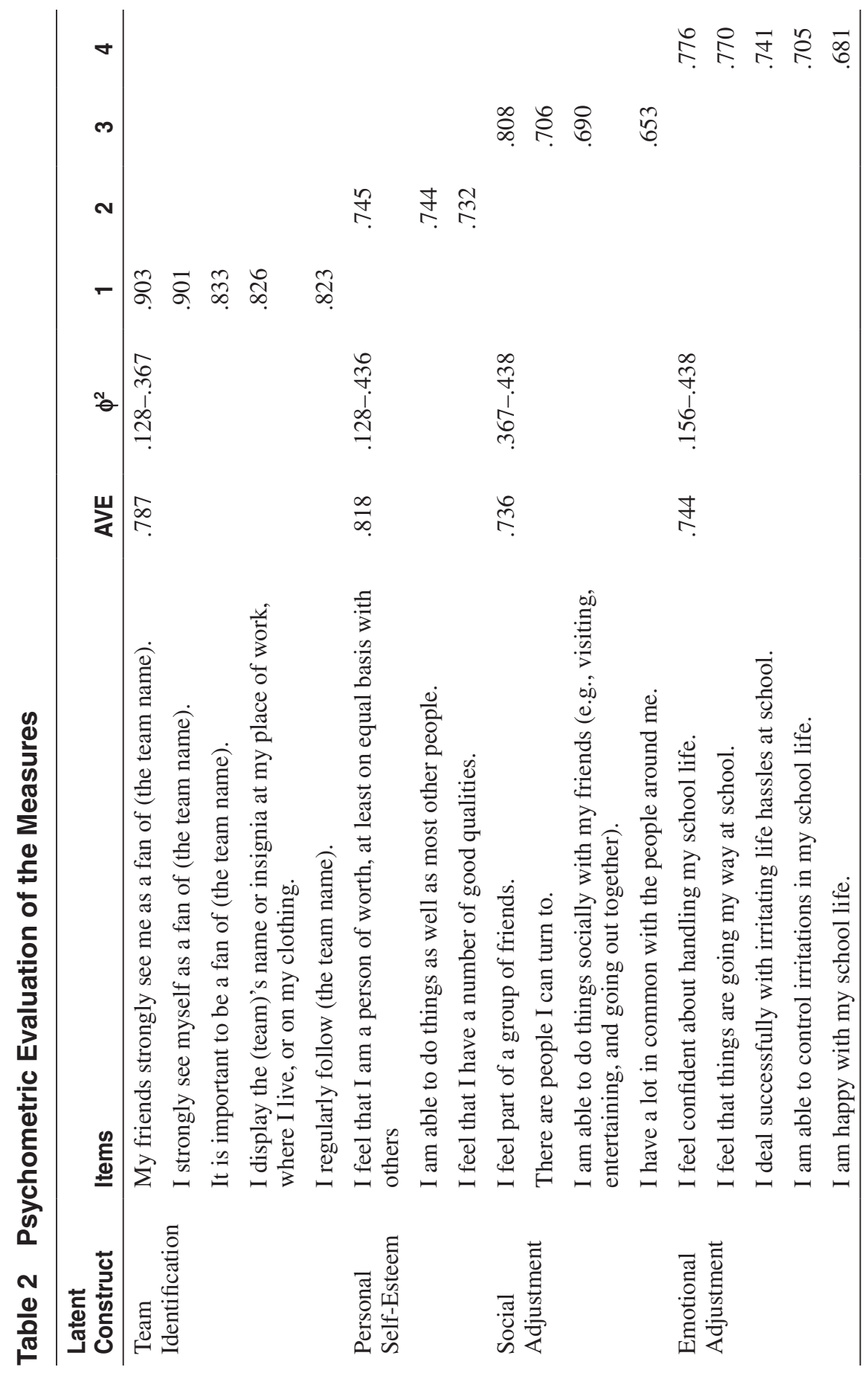




\section{Table 3 Decomposition of Effects with Standardized Values}

\begin{tabular}{llccc}
\hline Outcome & Predictor & \multicolumn{2}{c}{ Effects } \\
\hline & & Direct & Indirect & Total \\
\cline { 2 - 4 } Personal Self-Esteem & Team Identification & .361 & & .361 \\
$R^{2}=.130$ & & & & \\
Emotional Adjustment & Team Identification & & $.119+.183+.231$ & .533 \\
$R^{2}=.695$ & Personal Self-Esteem & .332 & & .332 \\
& Social Adjustment & .455 & & .455 \\
Social Adjustment & Team Identification & .425 & .183 & .608 \\
$R^{2}=.637$ & Personal Self-Esteem & .508 & & .508 \\
\hline
\end{tabular}

had a direct positive impact on social adjustment $(t=6.471, p<.05)$. These direct relationships also revealed the meditating role of personal self-esteem between team identification and social adjustment. Therefore, about 59\% of the variance in social adjustment was explained by both the direct and indirect relationships with team identification.

Finally, in contrast to social adjustment, team identification did not have a direct impact on students' emotional adjustment $(t=.603, p>.05)$. However, personal self-esteem $(t=3.355, p<.05)$ and social adjustment $(t=4.703, p<.05)$ directly led to students' emotional adjustment. These direct effects also triggered the meditating roles of personal self-esteem and social adjustment. In other words, team identification had a direct significant impact on personal self-esteem and social adjustment, which in turn influenced emotional adjustment. As a result, these determinants comprised completely of the direct and indirect effects accounted for approximately $52 \%$ of the variance in emotional adjustment. Finally, standardized parameter estimates for the structure components are presented in Figure 2.

\section{Discussion and Conclusions}

A number of scholars and administrators have paid significant attention to the nonacademic environment (e.g., intercollegiate athletics) which facilitates social and emotional adaptation to college life and stimulates positive academic motivation. The major goal of the study was to gain a better understanding of how intercollegiate athletics, one of the nonacademic environments in higher education, is associated with students' social and emotional adjustment. Specifically, theoretical propositions derived from social identity theory (Tajfel, 1981) and the team identification-psychological health model (Wann, 2006) were employed to explain related findings.

\section{Effects of Team identification on Personal Self-Esteem}

One of the findings from the decomposition of the SEM specified that a significant causal relationship between team identification and personal self-esteem exists. Several researches determined that students' overall emotional evaluation of 


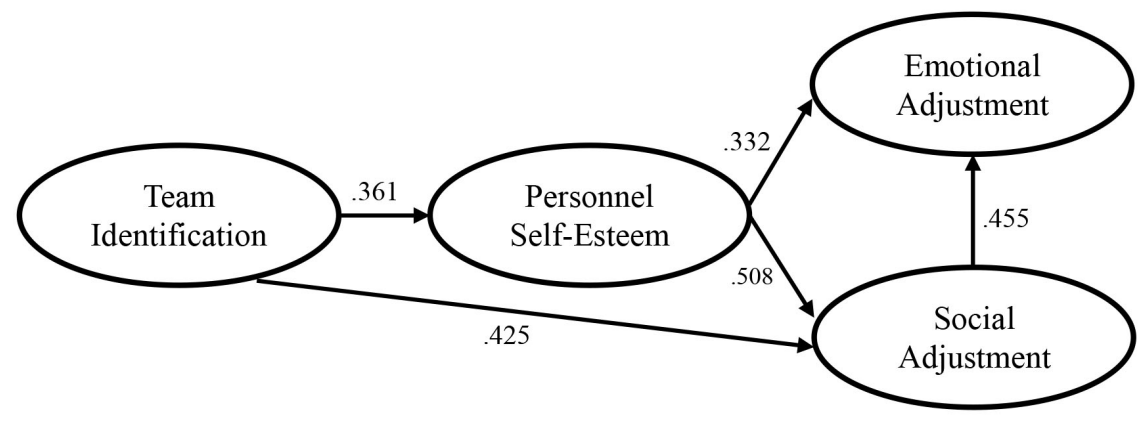

Figure 2 - The Full SEM Model Labeled With the Significant Standardized Effects

themselves is enhanced when they are strongly attached to an institution of higher education (Pedrotti, Edwards, \& Lopez, 2008; Pittman \& Richmond, 2007, 2008; Shankland, Genolini, Franca, Guelfi, \& Ionescu, 2010). Our findings imply that a positive attachment to a certain intercollegiate athletic program not only provides students the opportunity to involve themselves in a certain social group, but also improves individual self-esteem in their collegiate life. As a result, intercollegiate athletics that enhance students' self-esteem are demonstrated as one of the factors assisting in school adjustment. This was parallel with the social identity theory assertion that an individual could improve personal self-esteem through belonging to a social group (Tajfel, 1981; Tajfel \& Turner, 1979). Findings were also consistent with the team identification-psychological health model conceptualized by Wann (2006). He purported that emotional attachment to a certain team predicts an individual's psychological well-being, through active interaction and sharing personal self-concepts with social group members. Accordingly, the current study suggests that identification with intercollegiate athletics in higher education could allow students to improve their personal self-concept via social interactions with other students. From a practical standpoint, this finding further suggests that the benefits to a university that supports intercollegiate athletics go beyond mere revenue generation and appear to impact students' well-being.

\section{Effects of Personal Self-Esteem on Social/Emotional Adjustment}

Findings indicated that personal self-esteem is positively associated with social and emotional adjustment. Firstly, personal self-esteem had a direct effect on social adjustment which in turn played a mediating role between team identification and social adjustment. Findings were consistent with Tao, Dong, Pratt, Hunsberger, and Pancer (2000). They found that students with high levels of personal self-esteem derived from a sense of belonging to the university would experience a high level of social adjustment as compared with those individuals having a low level of personal self-esteem. Credé and Niehorster (2012) also indicated that adjustment 
to college is determined by personal self-esteem as students with high levels of personal self-esteem were easily involved in social relationships. In other words, positive evaluations of self could lead to higher levels of social competence facilitating social adjustment to college.

Secondly, personal self-esteem had a direct effect on emotional adjustment. The impact of personal self-esteem on emotional adjustment is supported by Simek (2013). He specified that personal self-esteem is significantly related to positive (e.g., happiness, satisfaction with life, etc.) and negative (e.g., fears, anxiety, etc.) aspects of subjective well-being. Simek's (2013) findings were parallel to those of Wann et al. (1999), confirming that personal self-esteem was correlated with various emotional conditions. Thus, the significant causal relationship between personal self-esteem and emotional adjustment identified in this study was fairly evident.

Although there has been no research directly examining the mediating role of personal self-esteem in the relationship between team identification and school adjustment, the current findings provide favorable evidence that this might be the case in higher education. Indeed, research indicates that for individuals who are collectively affiliated, personal self-esteem seems to be the basic underlying factor in the relationship between team identification and social and emotional well-being (Wann, 2006). In addition, the enhanced personal self-esteem nurtured by social group connections was an important element in predicting well-being and school adjustment. In this regard, this finding suggests that intercollegiate athletic programs can have a positive effect on students' well-adjusted school life.

\section{Effects of Team Identification on Social/Emotional Adjustment}

Another interesting finding derived from the current investigation was that team identification was directly and indirectly associated with school adjustment. Firstly, student's team identification toward the intercollegiate athletic team had a direct effect on student's social adjustment. Wann and Pierce (2005) purported that an attachment to a certain team was associated with social aspects of well-being as team identification readily created connection with in-group members. According to social identity theory (Tajfel, 1981), a sense of belonging to a certain group could generate the intangible benefits of social group membership. The levels of team identification in higher education might regulate the extent to which students are involved in active interaction with other students (Tajfel, 1981; Tajfel \& Turner, 1979). As a result, a student who highly identifies with his or her team is likely not only to seek social groups, but also to have the enhanced self-worth associated with intermingling with the in-group members (Arndt et al., 2002). These theoretical schemes evidently supported our findings that an increase in team identification had a direct impact on an increase in social adjustment for students in higher education.

Secondly, although team identification was not directly associated with students' emotional adjustment in this study, the positive self-evaluation and social connection with other students had a direct impact on emotional adjustment. In other words, development in the level of team identification indirectly assisted with the student's emotional adjustment through positive social associations and selfesteem. Findings support the connection between the role of team identification in sociopsychological well-being and students' social and emotional structure in 
campus life in higher education. Therefore, understanding a theoretical link between models of team identification that focus primarily on psychological well-being (e.g., Wann, 2006) and those that focus primarily on school adjustment (e.g., Credé \& Kuncel, 2008) has provided additional support for the importance of intercollegiate athletics in higher education and has clarified why administrators in academics should consider a prominent relationship with intercollegiate athletics.

\section{Practical Implications}

Findings provide promising evidence that intercollegiate athletics may assist in students' social and emotional adjustment by stimulating active social interaction with in-group members. In particular, the current study suggests several prominent implications for college or university administrators. Firstly, college administrators need to highlight the impacts of intercollegiate athletics that affect school adjustment in higher education. For example, university orientation should spotlight social integration of intercollegiate athletic programs, especially targeting freshmen because they have a higher level of difficulty adjusting to new college environments. In addition, counselors need to reinforce attending intercollegiate athletic games for a way to better interact with peers in the complex nature of school life. While many factors play a role in a student's emotional adjustment to college life, the social adjustment becomes especially important for students who attend primarily residential institutions (Friedlander, Reid, Shupak, \& Cribbie, 2007). In this regard, our findings suggest that an intervention of college administrators and faculties regarding the social aspect of intercollegiate athletic events could be addressed for a better quality of school life.

Secondly, as intercollegiate athletics improve student's adjustment, there is evident need for athletic promotions to assist students' team attachment. From a practical sense, there are several ways in which a university or college athletics department can further enhance student engagement with its athletics programs. Among these are the culture-building events that occur when new students arrive on campus. For example, institutions could promote "pep-rally" like activities where students learn the fight song, cheer and attendance rituals, and actually experience the college game atmosphere before the start of the season. These activities could occur in a number of settings, including new student orientation or a final preseason football scrimmage. Toma (2003) suggests that promotion of these rights and rituals are an important aspect of the institutional identity of the university. In addition, athletic departments can implement more student-focused activities such as student booster clubs and student tailgating events. Building from the BIRGing and CORFing literature (Wann and Branscombe, 1990), the increase of fan identification for students as a result of these activities would be a worthwhile endeavor for athletic organizations. Such examples could include students-only "meet and greets", special recognition at events, promotional items such as apparel and memorabilia, aspects that are usually reserved for major donors and traditional booster clubs and affinity groups.

Finally, while the findings of the current study extend previous literature, it is interesting to understand the context in which these findings have occurred. Previous literature has supported the relationship of fan identification and self-esteem, but the fact that the findings of the current study occurred during such an age of social media is in itself interesting to note. Gray, Vitak, Easton and Ellison (2013) suggest 
that one of the consequences of social media is the reliance of college students of staying engaged with their high school peer groups, which could further inhibit the student's social adjustment to college. While not a focus of the current study, the social nature of event attendance further promotes connection to the university and its athletic teams. Thus, it is the "active social interaction" that becomes even more important in the present time. While students who highly identified are more likely to attend the game of the team and to express as being a fan, it is easy to interact with other fans and increases sense of belonging that supports social adjustment. This phenomenon becomes even more evident with the increase in student-centric affinity groups created by university athletic departments.

\section{Limitations and Future studies}

Beyond the contribution of the research, there are some potential limitations concerning the results of the study. First, the results of the investigation may not represent institutions that vary in terms of region, athletic classifications or student makeup because the sample was confined to a convenient sample of undergraduate students in a major public university in the south region of the United States. It could be argued that students have a distinctive level of team identification and expectations placed on school life in different locations, athletic classifications, and years in school, which may affect the altered pattern of affiliations with intercollegiate athletics. Thus, future studies should be inclusive of larger groups in diverse locations.

Second, while the focus of this investigation involved college athletics programs on the whole, there was not a distinction made in the survey instrument to determine differences among the various sports that make up the overall programs. Considering that aspects of team identification may vary depending on the sport involved, future research could include specific sports as moderating variables.

Finally, since the current investigation is limited to analyzing the effects of team identification on social and emotional adjustment, it may be useful for future studies to further examine the value of academic adjustment to a student's adaptation to college life. While an academic success is potentially more prominent in higher education, a number of studies have indicated that social and emotional adjustments are correlated with academic demands such as enthusiasm to learn (Boesel \& Fredland, 1999; Brewer \& Gardner, 1996; Credé \& Niehorster, 2012; Engle \& Theokas, 2010; Horn \& Carroll, 2006). Therefore, academic adjustment should be conceptualized in this line of research to better understand how the intricate nature of college life is attenuated by intercollegiate athletics, which enhance the sense of a university community.

\section{References}

Arndt, J., Greenberg, J., Schimel, j., Pyszczynski, T., \& Solomon, S. (2002). To belong or not to belong, that is the question: Terror management and identification with gender and ethnicity. Journal of Personality and Social Psychology, 83(2), 26-43. PubMed doi:10.1037/0022-3514.83.1.26

Bentler, P.M., \& Hu, E.J.C. (2005). EQS 6.1 for Windows user's guide. Encino, CA: Multivariate Software, Inc. 
Bettencourt, B.A., \& Dorr, N. (1997). Collective self-esteem as a mediator of the relationship between allocentrism and subjective well-being. Personality and Social Psychology Bulletin, 23(9), 955-964. doi:10.1177/0146167297239005

Boesel, D., \& Fredland, E. (1999). College for all? Is there too much emphasis on getting a 4-year college degree? Washington, DC: National Library of Education, Office of Educational Research and Improvement, U.S. Department of Education.

Boyle, B.A., \& Magnusson, P. (2007). Social identity and brand equity formation: A comparative study of collegiate sports fans. Journal of Sport Management, 21, 497-520.

Branscombe, N.R., \& Wann, D.L. (1991). The positive social and self-concept consequences of sports team identification. Journal of Sport and Social Issues, 15(2), 115-127. doi:10.1177/019372359101500202

Branscombe, N.R., \& Wann, D.L. (1994). Collective self-esteem consequences of outgroup derogation when a valued social identity is on trial. European Journal of Social Psychology, 24(6), 641-657. doi:10.1002/ejsp.2420240603

Brewer, M.B. (1979). In-group bias in the minimal intergroup situation: A cognitivemotivational analysis. Psychological Bulletin, 86(2), 307-324. doi:10.1037/00332909.86.2.307

Brewer, M.B., \& Gardner, W. (1996). Who is this "we"? Levels of collective identity and self-representations. Journal of Personality and Social Psychology, 71(1), 83-93. doi:10.1037/0022-3514.71.1.83

Cohen, S., Kamarck, T., \& Mermelstein, R. (1983). A global measure of perceived stress. Journal of Health and Social Behavior, 385-396. PubMed doi:10.2307/2136404

Cole, J.J. (1999). Aquatic microbiology for ecosystem scientists: new and recycled paradigms in ecological microbiology. Ecosystems (New York, N.Y.), 2(3), 215-225. doi:10.1007/ s100219900069

Correll, J., \& Park, B. (2005). A model of the ingroup as a social resource. Personality and Social Psychology Review, 9(4), 341-359. PubMed doi:10.1207/s15327957pspr0904_4

Credé, M., \& Kuncel, N.R. (2008). Study habits, skills, and attitudes: The third pillar supporting collegiate academic performance. Perspectives on Psychological Science, 3(6), 425-453. PubMed doi:10.1111/j.1745-6924.2008.00089.x

Credé, M., \& Niehorster, S. (2012). Adjustment to college as measured by the student adaptation to college questionnaire: A quantitative review of its structure and relationships with correlates and consequences. Educational Psychology Review, 24(1), 133-165. doi:10.1007/s10648-011-9184-5

Engle, J., \& Theokas, C. (2010). Top gap closers: Some public four-year colleges and universities have made good progress in closing graduation-rate gaps. Washington, DC: The Education Trust.

Fisher, R.J., \& Wakefield, K. (1998). Factors leading to group identification: A field study of winners and losers. Psychology and Marketing, 15(1), 23-40. doi:10.1002/(SICI)15206793(199801) 15:1<23::AID-MAR3>3.0.CO;2-P

Friedlander, L.J., Reid, G.J., Shupak, N., \& Cribbie, R. (2007). Social support, self-esteem, and stress predictors of adjustment to university among first-year undergraduates. Journal of College Student Development, 48(3), 259-274. doi:10.1353/csd.2007.0024

George, D., \& Mallery, P. (2000). SPSS for Windows: A simple guide and reference. Boston, MA: Allyn \& Bacon.

Gerdes, H., \& Mallinckrodt, B. (1994). Emotional, social, and academic adjustment of college students: A longitudinal study of retention. Journal of Counseling and Development, 72(3), 281-288. doi:10.1002/j.1556-6676.1994.tb00935.x

Gray, R., Vitak, J., Easton, E.W., \& Ellison, N.B. (2013). Examining social adjustment to college in the age of social media: Factors influencing successful transitions and persistence. Computers \& Education, 67, 193-207. doi:10.1016/j.compedu.2013.02.021 
Hair, J.H., Black, W.C., Babin, B.J., Anderson, R.E., \& Tatham, R.L. (2006). Multivariate data analysis (6th ed.). Upper Saddle River, NJ: Prentice Hall.

Heere, B., \& James, J.D. (2007a). Sports teams and their communities: Examining the influence of external group identities on team identity. Journal of Sport Management, 21(3), 319-337.

Heere, B., \& James, J.D. (2007b). Stepping outside the lines: Developing a multi-dimensional team identity scale based on social identity theory. Sport Management Review, 10, 65-91. doi:10.1016/S1441-3523(07)70004-9

Herzog, A.R., \& Bachman, J.G. (1981). Effects of questionnaire length on response quality. Public Opinion Quarterly, 45(4), 549-559. doi:10.1086/268687

Horn, L., \& Carroll, C.D. (2006). Placing College Graduation Rates in Context: How 4-Year College Graduation Rates Vary with Selectivity and the Size of Low-Income Enrollment (NCES 2007-161). U.S. Department of Education, National Center for Education Statistics. Washington, DC: U.S. Government Printing Office.

Houston, B.K. (1971). Sources, effects, and individual vulnerability of psychological problems for college students. Journal of Counseling Psychology, 18(2), 157-165. doi: $10.1037 / \mathrm{h} 0030622$

Hu, L.T., \& Bentler, P.M. (1999). Cutoff criteria for fit indexes in covariance structure analysis: Conventional criteria versus new alternatives. Structural Equation Modeling, 6(1), 1-55. doi:10.1080/10705519909540118

Kelloway, E.K. (1998). Using LISREL for structural equation modeling: A researcher's guide. Sage (Atlanta, Ga.).

Koo, G.Y., \& Hardin, R. (2008). Difference in interrelationship between spectators' motives and behavioral intentions based on emotional attachment. Sport Marketing Quarterly, 17(1), 30-43.

Kwon, H.H., \& Armstrong, K.L. (2004). An exploration of the construct of psychological attachment to a sport team among college students: a multidimensional approach. Sport Marketing Quarterly, 13(2), 94-103.

Lee, S., Shin, H., Park, J., \& Kwon, O. (2010). "A Brand Loyalty Model Utilizing Team Identification and Customer Satisfaction in the Licensed Sports Product Industry" Published in the International Council for Health, Physical Education, Recreation, Sport, and Dance (ICHPER-SD). Journal of Research, 5, 60-67.

Lokitz, B.D., \& Sprandel, H.Z. (1976). The First Year: A Look at the Freshman Experience. Journal of College Student Personnel, 17(4), 274-279.

Madrigal, R. (1995). Cognitive and affective determinants of fan satisfaction with sporting event attendance. Journal of Leisure Research, 27(3), 205-227.

Madrigal, R., \& Chen, J. (2008). Moderating and mediating effects of team identification in regard to causal attributions and summary judgments following a game outcome. Journal of Sport Management, 22(6), 717-733.

Mertler, C.A., \& Vannatta, R.A. (2001). Advanced and multivariate statistical methods: Practical application and interpretation. Los Angeles, CA: Pyrczak.

McDonald, H., \& Adam, S. (2003). A comparison of online and postal data collection methods in marketing research. Marketing Intelligence \& Planning, 21(2), 85-95. doi:10.1108/02634500310465399

Murrell, A.J., \& Dietz, B. (1992). Fan support of sport teams: The effect of a common group identity. Journal of Sport \& Exercise Psychology, 14(1), 28-39.

Nunnally, J.C., \& Bernstein, I.H. (1994). Psychometric theory (3rd ed.). New York: McGraw Hill.

Oakes, P.J., \& Turner, J.C. (1980). Social categorization and intergroup behaviour: Does minimal intergroup discrimination make social identity more positive? European Journal of Social Psychology, 10(3), 295-301. doi:10.1002/ejsp.2420100307 
Pedrotti, J.T., Edwards, L.M., \& Lopez, S.J. (2008). Working with multiracial clients in therapy: Bridging theory, research, and practice. Professional Psychology, Research and Practice, 39(2), 192-201. doi:10.1037/0735-7028.39.2.192

Pittman, L.D., \& Richmond, A. (2007). Academic and psychological functioning in late adolescence: The importance of school belonging. Journal of Experimental Education, 75(4), 270-290. doi:10.3200/JEXE.75.4.270-292

Pittman, L.D., \& Richmond, A. (2008). University belonging, friendship quality, and psychological adjustment during the transition to college. Journal of Experimental Education, 76(4), 343-362. doi:10.3200/JEXE.76.4.343-362

Rich, A.R., \& Scovel, M. (1987). Causes of depression in college students: A cross-lagged panel correlational analysis. Psychological Reports, 60(1), 27-30. doi:10.2466/ pr0.1987.60.1.27

Rosenberg, M. (1979). Conceiving the self, 1979. New York: Basic.

Russell, D., Peplau, L.A., \& Ferguson, M.L. (1978). Developing a measure of loneliness. Journal of Personality Assessment, 42(3), 290-294. PubMed doi:10.1207/ s15327752jpa4203_11

Russell, D.W. (1996). UCLA Loneliness Scale (Version 3): Reliability, validity, and factor structure. Journal of Personality Assessment, 66(1), 20-40. PubMed doi:10.1207/ s15327752jpa6601_2

Sauro, J., \& Lewis, J.R. (2011). When designing usability questionnaires, does it hurt to be positive? In: Proceedings ACM CHI 201 Conference on Human Factors in Computing Systems 2011, 2215-2224. doi:10.1145/1978942.1979266

Shankland, R., Genolini, C., França, L.R., Guelfi, J.D., \& Ionescu, S. (2010). Student adjustment to higher education: The role of alternative educational pathways in coping with the demands of student life. Higher Education, 59(3), 353-366. doi:10.1007/ s10734-009-9252-7

Simek, O.F. (2013). Structural relations of personal and collective self-esteem to subjective well-being: Attachment as moderator. Social Indicators Research, 110(1), 219-236. doi:10.1007/s11205-011-9927-1

Sutton, W.A., McDonald, M.A., Milne, G.R., \& Cimperman, J. (1997). Creating and fostering fan identification in professional sport. Sport Marketing Quarterly, 6(1), 15-22.

Swanson, S.R., Gwinner, K., Larson, B.V., \& Janda, S. (2003). Motivations of college student game attendance and word-of-mouth behavior: The impact of gender differences. Sport Marketing Quarterly, 12(3), 151-162.

Tajfel, H. (1981). Human groups and social categories: Studies in social psychology. CUP Archive.

Tajfel, H., \& Turner, J. C. (1979). An integrative theory of intergroup conflict. The social psychology of intergroup relations, 33-47.

Tao, S., Dong, Q., Pratt, M.W., Hunsberger, B., \& Pancer, S.M. (2000). Social support relations to coping and adjustment during the transition to university in the People 's Republic of China. Journal of Adolescent Research, 15(1), 123-144. doi:10.1177/0743558400151007

Theodorakis, N. D., Wann, D. L., \& Weaver, S. (2012). An Antecedent Model of Team Identification in the Context of Professional Soccer. Sport Marketing Quarterly, 21(2).

Trail, G., Anderson, D.F., \& Fink, J. (2000). A theoretical model of sport spectator consumption behavior. International Journal of Sport Management, 1(3), 154-180.

Toma, J.D. (1998). Representing the university: The uses of intercollegiate athletics in enhancing institutional identity. Paper presented at the American Education Research Association Annual Meeting (pp. 1-2). San Diego, California.

Toma, J.D. (2003). Football U: Spectator sports in the life of the American university. Ann Arbor, MI: University of Michigan Press. 
Turner, J.C. (1975). Social comparison and social identity: Some prospects for intergroup behavior. European Journal of Social Psychology, 5(1), 1-34. doi:10.1002/ ejsp. 2420050102

U.S. Department of Education. (2006). Digest of Education Statistics, 2005. No. NCES 2006-005. Washington, D.C.: U.S. Department of Education, National Center for Education Statistics.

Wann, D.L. (1996). Seasonal changes in spectators' identification and involvement with and evaluations of college basketball and football teams. The Psychological Record, 46(1), 201-215.

Wann, D.L. (2000). Further exploration of seasonal changes in sport fan identification: Investigating the importance of fan expectations. International Sports Journal, 4(1), 119-123.

Wann, D.L. (2006). Understanding the positive social psychological benefits of sport team identification: The team identification-social psychological health model. Group Dynamics, 10(4), 272-296. doi:10.1037/1089-2699.10.4.272

Wann, D.L., \& Branscombe, N.R. (1990). Die-hard and fair-weather fans: Effects of identification on BIRGing and CORFing tendencies. Journal of Sport and Social Issues, 14(2), 103-117. doi:10.1177/019372359001400203

Wann, D.L., \& Branscombe, N.R. (1993). Sports fans: Measuring degree of identification with the team. International Journal of Sport Psychology, 24(1), 1-17.

Wann, D.L., Brewer, K.R., \& Royalty, J.L. (1999). Sport fan motivation: Relationships with team identification and emotional reactions to sporting events. International Sports Journal, 3(2), 9-18.

Wann, D.L., Dunham, M.D., Byrd, M.L., \& Keenan, B.L. (2004). The five-factor model of personality and the psychological health of highly identified sport fans. International Sports Journal, 8(2), 28-36.

Wann, D.L., \& Pierce, S. (2005). The relationship between sport team identification and social well-being: Additional evidence supporting the team identification-social psychological health model. North American Journal of Psychology, 7(1), 117-124.

Wann, D.L., Tucker, K.B., \& Schrader, M.P. (1996). An exploratory examination of the factors influencing the origination, continuation, and cessation of identification with sports teams. Perceptual and Motor Skills, 82(3), 995-1001. doi:10.2466/pms.1996.82.3.995

Wann, D.L., \& Weaver, S. (2009). Understanding the relationship between sport team identification and dimensions of social well-being. North American Journal of Psychology, 11(2), 219-230. 